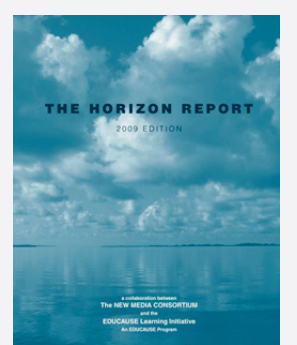

\title{
The Horizon Report: prospección tecnológica para la enseñanza
}

por Pedro García Pilán

Johnson, L., Levine, A. \& Smith, R. (2009). The 2009 Horizon Report. Austin, Texas: The New Media Consortium. http://www.nmc.org/pdf/2009-Horizon-Report.pdf

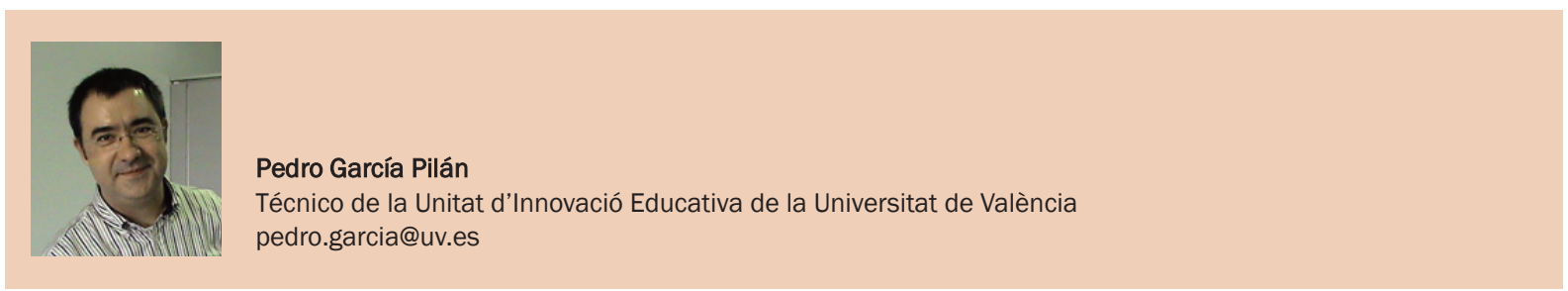

Fecha presentación: 10/09/2009

I Aceptación: 14/10/2009

| Publicación: 04/12/2009

Por sexto año consecutivo, y como fruto de la colaboración entre New Media Consortium y EDUCAUSE, se pone a nuestra disposición el Informe Horizon (del informe del año pasado ya se dio cuenta en el $\mathrm{n}^{0} 1$ de @tic: cf. Algarabel, 2008). The Horizon Report es un estudio realizado por un nutrido comité internacional de expertos (con mayoría estadounidense), procedentes tanto de universidades como de centros de investigación y empresas privadas, que identifica las principales tecnologías de la información y las comunicaciones emergentes, al tiempo que anuncia cuáles de éstas se aplicarán al ámbito educativo.

Tal ejercicio de análisis y prospectiva, realizado mediante la aplicación sistemática del método Delphi, se plasma en la detección de seis tecnologías o prácticas emergentes, cuya implantación se estructura de manera temporal en tres horizontes: el primero predice las tecnologías que se incorporarán de manera significativa a la enseñanza a lo largo del primer año; el segundo anuncia lo que sucederá en los próximos dos o tres años; por último, el tercero detecta las tecnologías a implantar dentro de los próximos cuatro o cinco años.

Así, dentro del primer horizonte tenemos, en primer lugar, los móviles y los sistemas de computación en nube. Respecto a los primeros, se destaca que los espectaculares desarrollos alcanzados en los últimos años ha permitido borrar la frontera entre un teléfono y un ordenador (de hecho, apenas se habla ya de teléfono: el término "móvil" aparece asociado a otras muchas funciones que han desbordado el ámbito estrictamente telefónico), lo que da pie a insistir una y otra vez en la necesidad de aplicar estas herramientas a la enseñanza aunque, a decir verdad, ni se acaban de apuntar ideas concretas sobre cómo hacerlo, ni -lo que quizás es peor- se sugiere en qué mejoraría una enseñanza basada en los modernos y potentes dispositivos móviles (dentro de los cuales el iPhone es mencionado de manera expresa en varias ocasiones: podría pensarse que no en vano hay personal de Apple en el consejo asesor del Proyecto Horizon). Al respecto, podríamos apuntar que la posibilidad de disponer de una conexión a Internet desde casi cualquier lugar puede reportar ventajas evidentes, pero no está tan claro que necesariamente tenga que desprenderse de ello la necesidad de aplicar masivamente esta tecnología a la enseñanza. Y es que una cosa es la previsión de que cada vez más gente se conecte a la red utilizando un dispositivo de bolsillo, y otra que los procesos de enseñanza-aprendizaje mejoren sensiblemente mediante el recurso a pantallas que son, evidentemente, de calidad, pero de pequeñas dimensiones para según qué propósitos. Por otra parte, quizás cabría apuntar que el elevado precio de este tipo de dispositivos permite, como mínimo, mostrar un cierto escepticismo respecto a su implantación masiva en la enseñanza en el horizonte propuesto (no olvidemos que esta previsión es de "un año o menos").

Menos objeciones cabe hacerle a la segunda de las tecnologías propuestas para el primer horizonte. Y es que, efectivamente, los servicios de computación en nube (data farms: servidores interconectados de gran capacidad de procesamiento y almacenamiento) no sólo han alcanzado un 
desarrollo tal que ha contribuido a cambiar nuestras vidas ( $\sin$ ir más lejos, aplicaciones de uso cotidiano como Google o You Tube utilizan la nube como plataforma), sino que ofrecen alternativas gratuitas o a bajo coste a los gravosos paquetes de software o dispositivos de hardware que hasta hace poco nos veíamos obligados a comprar. No obstante, también se nos advierte en el informe que manejamos de algunos riesgos de esta alternativa: las aplicaciones basadas en tecnología nube son ofrecidas por proveedores (es decir, empresas) en tiempo real; en consecuencia, subir nuestra información a la nube supone confiar en ese proveedor, al margen de los vaivenes del mercado o de condiciones cambiantes de cualquier otro tipo.

En un segundo estrato u horizonte temporal encontramos el Geo-Everything y la web personal. La primera de estas tecnologías -estrechamente vinculada al desarrollo de la web 2.0-, permite asignar coordenadas espaciales a prácticamente cualquier tipo de información, lo que, evidentemente, supone la posibilidad de efectuar visualizaciones de múltiples tipos de fenómenos de cualquier área científica o de conocimiento. Así, podríamos afirmar que, gracias al geotodo, la mapificación en la enseñanza desborda definitivamente el ámbito de la geografía, lo que sin duda abre nuevos horizontes de manera generalizada. Dejando claro este punto, también cabe advertir del peligro de utilizar esta tecnología de manera irreflexiva, es decir, en lugar de plantearse previamente qué necesidades de la enseñanza permite cubrir o mejorar el geo-todo, dar por hecho que, ya que se dispone de éste, debe ser aplicado para lo que sea, peligro que se vislumbra tras la lectura de las páginas 16-17 del informe.

En cuanto a la web personal, se pone de relieve la importancia de herramientas como iGoogle, Delicious o Diigo. Pero, mucho más allá de estos ejemplos concretos, resulta evidente que las crecientes posibilidades de gestión personal de múltiples contenidos en línea permiten replantear las interacciones que se establecen a lo largo de los procesos de enseñanza-aprendizaje, ya que la web personal no sólo es susceptible de fomentar la formación de contenidos individualizados (según las preferencias y necesidades de cada uno), sino que, además, permite el desarrollo de nuevas formas de aprendizaje colaborativo.

En el tercer horizonte de aplicación encontramos, en primer lugar, las aplicaciones con conciencia semántica (herramientas que registran el contexto en que se expresa la información, con capacidad para extraer significados integrados y proporcionar formas personalizadas de acceso a los contenidos). Aunque hay en estos momentos dos planteamientos teóricos para desarrollar la capacidad semántica de la web (el bottom-up y el top-down), en ambos casos se trata de herramientas diseñadas para utilizar los significados de información disponible en Internet, realizando conexiones que requerirían de otra manera una cantidad desmedida de tiempo y esfuerzo. Aunque se nos advierte que los ejemplos de aplicaciones con conciencia semántica a la enseñanza son todavía escasos, se nos ilustra del potencial de este tipo de tecnologías a través de herramientas como Twine o WorldMapper, entre otras. Se trata, en definitiva, de herramientas que han demostrado su utilidad en el ámbito de la investigación; tiempo es, pues, de plantearse su integración en la enseñanza.

Finalmente, nos encontramos con los "objetos inteligentes”, es decir, objetos que, como el iPhone, saben acerca de sí mismos y de su entorno y que, al conectar el mundo físico con el de la información, vinculan el mundo real con el vir- tual. Así, a través de proyectos como Semapedia, que permiten indicar la ubicación física de objetos etiquetados previamente, se prevé una progresiva difuminación de la línea entre el objeto tangible y la información digital. La trascendencia de este tipo de objetos en áreas como la biblioteconomía es evidente, pero también se nos proporcionan algunas sugerencias de su uso en áreas tan dispares como la arqueología o la medicina.

El informe termina con una descripción, sucinta pero suficiente, de la metodología empleada para realizar el estudio, lo que es de agradecer, ya que nos permite no sólo controlar el proceso de elaboración del informe, sino saber quiénes y bajo qué presupuestos están implicados en la elaboración del mismo. Así, parece claro que la aplicación de la técnica Delphi (útil siempre que se tenga una finalidad prospectiva) ha sido sumamente rigurosa, lo que no permite objetar nada al respecto. Con todo, sí podemos interrogarnos acerca de algunos supuestos implícitos en las preguntas a las que pretende contestar el informe.

Por ejemplo, y como punto de partida, se nos informa de que las tecnologías emergentes de las que se nos hablará serán las que probablemente se generalicen durante los plazos establecidos en la enseñanza (pág.3), cuando poco más adelante se nos advierte de que se trata de buscar deliberadamente tecnologías que en el momento presente no gozan de demasiada aceptación en el ámbito académico (p.7). Ahora bien, tales precauciones no impiden afirmar que estas mismas tecnologías marcarán las tendencias que determinarán la forma de trabajar en la enseñanza ("that will shape the way we work in academia") en los horizontes temporales oracularmente establecidos. Al respecto, resulta interesante constatar cómo nos encontramos ante un claro ejemplo de cómo las TIC sirven para construir significaciones sociales que permiten construir positivamente un futuro imaginado en clave tecnológica, línea en la que vienen incidiendo últimamente sociólogos como Daniel Horacio Cabrera (2003) o Alberto Ribes Leiva (2007). Desde esta perspectiva, se pone de manifiesto el enorme valor discursivo y simbólico de unas tecnologías ligadas indisolublemente, de manera implícita o explícita, a la noción de progreso: primero imaginamos un futuro tecnológico (y por tanto, mejor), y luego lo convertimos en posibilidad real al hacer inevitable la adaptación al mismo, en un proceso de institucionalización claramente inteligible tanto desde propuestas teóricas como la clásica de Merton sobre "la profecía que se autocumple", como desde las de Castoriadis (1975) o Taylor (2004) acerca de la construcción de los imaginarios sociales.

$\mathrm{Al}$ margen de este tipo de consideraciones teóricas, en el informe hay otras afirmaciones que son claramente insostenibles, como cuando, a partir de un ejemplo concreto, se pretende generalizar la idea de que el uso de juegos en la enseñanza aumenta el compromiso cívico ("civic engagement”) del grupo (p.5). Y es que una cosa es destacar la importancia del juego como herramienta de aprendizaje -algo sobre lo que ya escribió con acierto y profusión Huizinga hace muchos años (1935)- y otra es presentarlo como una panacea liberadora, independientemente de los objetivos educativos del contexto en que nos situemos. También cabría advertir que no se nos dice nada concreto acerca de cómo conectar las tendencias más significativas detectadas al principio del informe (inteligencia colectiva, alfabetismo visual, globalización, etc.), con ninguna de las seis técnicas que, según se anuncia, aplicaremos a la enseñanza irremediablemente durante el próximo lustro. 
Pese a lo señalado, nos encontramos ante un informe interesante, que proporciona información clara y abundante sobre un material que resulta imprescindible conocer (es una lástima que alguno de los links indicados ya no funcionen). Pero tampoco estaría de más, ahora que llevamos ya seis informes anuales consecutivos, intentar hacer balance, y ver qué tecnologías se han implantado realmente en la enseñanza dentro de los horizontes previstos. Evidentemente, tal ejercicio de evaluación debería efectuarse de manera minuciosa, pero un simple vistazo a informes anteriores nos permitirá constatar, por ejemplo, cómo cinco años después de pronosticar una extensión generalizada de los Learning Objects en el primer horizonte, todavía seguimos debatiendo a qué nos referimos cuando hablamos de los mismos, por no hablar de la anunciada relevancia de los gráficos vectoriales bidimensionales -Scalable Vector Graphics-, también en el año 2004, o de esa curiosa insistencia en la importancia de los móviles en varios informes consecutivos. En definitiva, un año después, siguen siendo plenamente válidas las observaciones realizadas desde estas mismas páginas acerca del informe correspondiente al año 2008: "si el aspecto educativo y el informático no se conjugan, la oferta no pasará de ser un menú de opciones que dificultan la acción educativa y disminuyen la usabilidad del sistema” (Algarabel, 2008: 83). Esperemos que el año próximo se haya avanzado algo en tan necesario ejercicio de reflexión.

\section{Bibliografía}

Algarabel, Salvador (2008). El futuro de la formación en tecnologías. @tic. revista d’innovació educativa, 1, pp.82-83. http://ojs.uv.es/index.php/attic/article/view/35/53

Cabrera, Daniel Horacio (2003). "Técnica" y "progreso" como significaciones imaginarias sociales. Elementos para una hermenéutica social de las "nuevas tecnologías de la información y la comunicación”. Anthropos. Huellas del conocimiento, 198, pp.106-125.

Castoriadis, Cornelius (1975). La institución imaginaria de la sociedad, 2: El imaginario social y la institución. Barcelona: Tusquets, 1989. Trad. de Antoni Vicens Llorens.

Huizinga, Johan (1938). Homo ludens. Madrid: Alianza, 1994. Trad. de Eugenio Imaz.

Merton, Robert K. (1949). Teoría y estructura sociales. México: F.C.E., 1995. Trad. de Florentino M. Torner. Ribes Leiva, Alberto J. (2007). Seducción, comunidad y desigualdad: el ciberespacio y sus consecuencias sociopolíticas", Anduli. Revista Andaluza de Ciencias Sociales, 7 , pp.53-76.

Taylor, Charles (2004): Imaginarios Sociales Modernos. Barcelona: Paidós, 2006. Trad. de Ramón Vilà Vernis. 